\title{
Validated Fall Risk Assessment Tools for Use with Older Adults: A Systematic Review
}

\section{Marcello Ruggieri, Biagio Palmisano, Giancarlo Fratocchi, Valter Santilli, Roberta Mollica, Anna Berardi \& Giovanni Galeoto}

To cite this article: Marcello Ruggieri, Biagio Palmisano, Giancarlo Fratocchi, Valter Santilli, Roberta Mollica, Anna Berardi \& Giovanni Galeoto (2019): Validated Fall Risk Assessment Tools for Use with Older Adults: A Systematic Review, Physical \& Occupational Therapy In Geriatrics, DOI: $10.1080 / 02703181.2018 .1520381$

To link to this article: https://doi.org/10.1080/02703181.2018.1520381

册Published online: 14 Jan 2019.

Submit your article to this journal

Џ Article views: 15

View Crossmark data \lceil 


\title{
Validated Fall Risk Assessment Tools for Use with Older Adults: A Systematic Review
}

\author{
Marcello Ruggieri ${ }^{a}$, Biagio Palmisano ${ }^{b}$, Giancarlo Fratocchi ${ }^{c}$, Valter Santillic, \\ Roberta Mollica ${ }^{c}$, Anna Berardi ${ }^{a}$, and Giovanni Galeoto ${ }^{d}$ (D) \\ aSapienza University of Rome, Rome, Italy; ${ }^{b}$ Department of Molecular Medicine, Sapienza \\ University of Rome, Rome, Italy; 'Department of Anatomical, Histological, Forensic and \\ Orthopaedic Sciences, Sapienza University of Rome, Rome, Italy; ${ }^{\mathrm{d} D e p a r t m e n t}$ of Public Health, \\ Sapienza University of Rome, Rome, Italy
}

\begin{abstract}
Aims: to find and describe, through a systematic review, validated assessment tool that evaluate the fall risk in older adults. Methods: MEDLINE, PEDro, CINAHL, and PsycINFO were consulted and no restrictions were applied to the year or country of publication but the searches were limited to studies published in English. Two authors independently identified eligible studies on the basis of inclusion criteria and extracted data. Results: Fifty-five eligible studies were identified, out of which 33 valued risk assessment tools emerged. The tools used the most were the Falls Efficacy Scale International and the Activities-specific Balance Confidence Scale with 15 and 6 studies respectively. Conclusions: The large number of tools reflects a strong tendency to create new instruments, with only a few of them recommended. To reach a gold standard, it would be good to try to validate the existing scales in more countries instead of creating new ones.
\end{abstract}

\section{ARTICLE HISTORY}

Received 22 December 2017

Accepted 31 August 2018

\section{KEYWORDS}

Fall risk assessment; aged; older; validation questionnaire; adults; systematic review

\section{Introduction}

Falls and fall-related injuries are a common and serious problem for older adults. People 65 and older have the highest risk of falling, with $30 \%$ of people older than 65 and $50 \%$ of people older than 80 falling at least once a year. ${ }^{1}$

The human cost of falling includes distress, pain, injury, loss of confidence, loss of independence, and mortality. Falling also affects the family members and carers of people who fall, carers may experience similar fall concern as older persons with regard to the risk of falling. Several studies showed that a history of falls in the person being cared for was associated with increased caregiver burden, even after controlling for functional status and comorbidities. Carers of persons who had fallen subsequently changed their social and work engagements for fear of leaving their care recipients 
alone. $^{2}$ Therefore, falling has an impact on quality of life, health, and healthcare costs. ${ }^{1}$ Older adults are particularly vulnerable to falls owing to agerelated musculoskeletal and joint weakness. Older adults are also susceptible to fracture injuries, which account for about half of all fall-related injuries. ${ }^{3}$ Apart from the physical burden of a fall, older people who survive falls tend to experience anxiety, loss of confidence, and fear of falling again. These feelings are associated with restriction or avoidance of daily activities, loss of independence, and reduced social activity or quality of life. ${ }^{3}$

Screening tools have generally been found to do a poor job at discriminating fallers from nonfallers. ${ }^{4,5}$ Nevertheless, some tools may be useful in particular settings, indeed most of them are designed for a particular environment (eg. hospital environment, nursing homes, extra-hospital environment, emergency departments). Moreover, fall risk assessments have demonstrated greater utility when combined with sound clinical judgment. A focused and user-friendly review of fall risk assessments should help clinicians and others use and potentially adopt current instruments more effectively. The data available in the literature allows for the identification of different fall risk assessment tools. Internationally, the tools used the most are the Falls Efficacy Scale International (FES-I) and the Activities-specific Balance Confidence Scale (ABC), both of which evaluate the fear of falling in community-dwelling older adults.

The purpose of this study was to find and describe, through a systematic review of observational cohort and cross-sectional studies, the questionnaires used for fall risk assessment in older adults at an international level. Specifically, this study aimed to identify the validated fall risk assessment tools and assess their settings, language, pathology, and psychometric properties.

\section{Methods}

\section{Criteria for considering studies for this review: Types of studies, types of participants and types of outcomes}

Studies that validated fall risk assessment tools in older adults were considered for review. Therefore, observational cohort and cross-sectional studies were included. Studies that validated fall risk assessment tools already utilized in their country of origin were excluded. Studies were limited to older adults who were healthy or had pathologic conditions and were living in a community or were hospitalized. Studies were included if the participants were 60 years or over, or if the range was extended to 60 and over. The primary outcome was the number of fall risk assessment tools that had been validated at an international level. Secondary outcomes were the psychometric properties of the tools. Therefore, the tools were stratified by setting. 


\section{Search methods for identification of studies, electronic searches}

The following electronic databases were searched and all potential studies were identified by two authors (MR, GG): MEDLINE, PEDro, CINAHL and PsycINFO

The Medical Subject Headings of the United States National Library of Medicine (MESH) was used to determine which search terms to use. The MESH terms used were (ACCIDENTAL FALL) and (AGED), from which the following results were obtained: (Falling; Falls; Falls, Accidental; Accidental Fall; Fall, Accidental; Slip and Fall; Fall and Slip; Aged; Elderly). The search strategy is shown in figure 1. It was constructed for MEDLINE and adapted to other databases.

\section{Selection of studies}

Before starting the review duplicate papers were filtered out using Endnote. Following guidelines of the Preferred Reporting Items for Systematic Reviews and Meta-Analyses (PRISMA) statement two authors (MR, GG) first screened titles and abstracts using the following inclusion criteria: validation, cultural and retrospective adaptation studies; studies on fall risk; sample age $\geq 60$ years old or with a range that was extended to the third age; tests, questionnaires, and scales that were operatordependent and self-administered; and studies that were related to both healthy and pathologic individuals. Then studies that met the criteria were subject to a full text review to determine if they should be included in the review.

\section{Data collection and analysis and assessment of risk of bias}

For each included study, we tried to obtain the following data and psychometric properties: authors; scale; language; sample (pathology); mean age, standard deviation, age range, and gender; setting; administration; Cronbach's $\alpha$; intraclass coefficient correlation (ICC); inter-item correlation

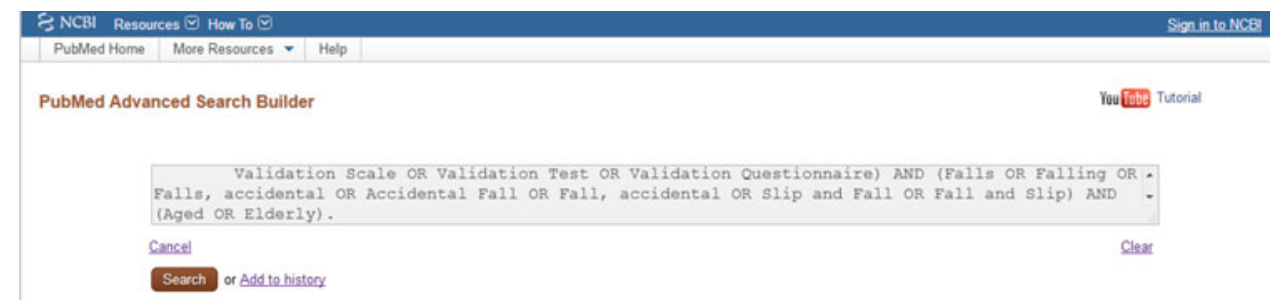

Figure 1. Search strategy. 
(IIC); and receiver operating characteristic (ROC) curve, (sensitivity, specificity, positive predictive value, and negativity predictive value).

The methodological quality of each of the selected studies was assessed using the Quality Assessment Tool for Observational Cohort and CrossSectional Studies.

\section{Results}

\section{Study selection: Description of the studies and results of the search}

The research identified 420 matches, of which 65 studies were selected after reading the abstracts. After reading the full text, we excluded 10 studies (which focused mainly on motor tests). Therefore, the review presents 55 different studies. The research steps are shown in Figure 2.

After following our inclusion and exclusion criteria, 33 fall risk assessment tools that were validated at an international level were identified (Appendix 1).

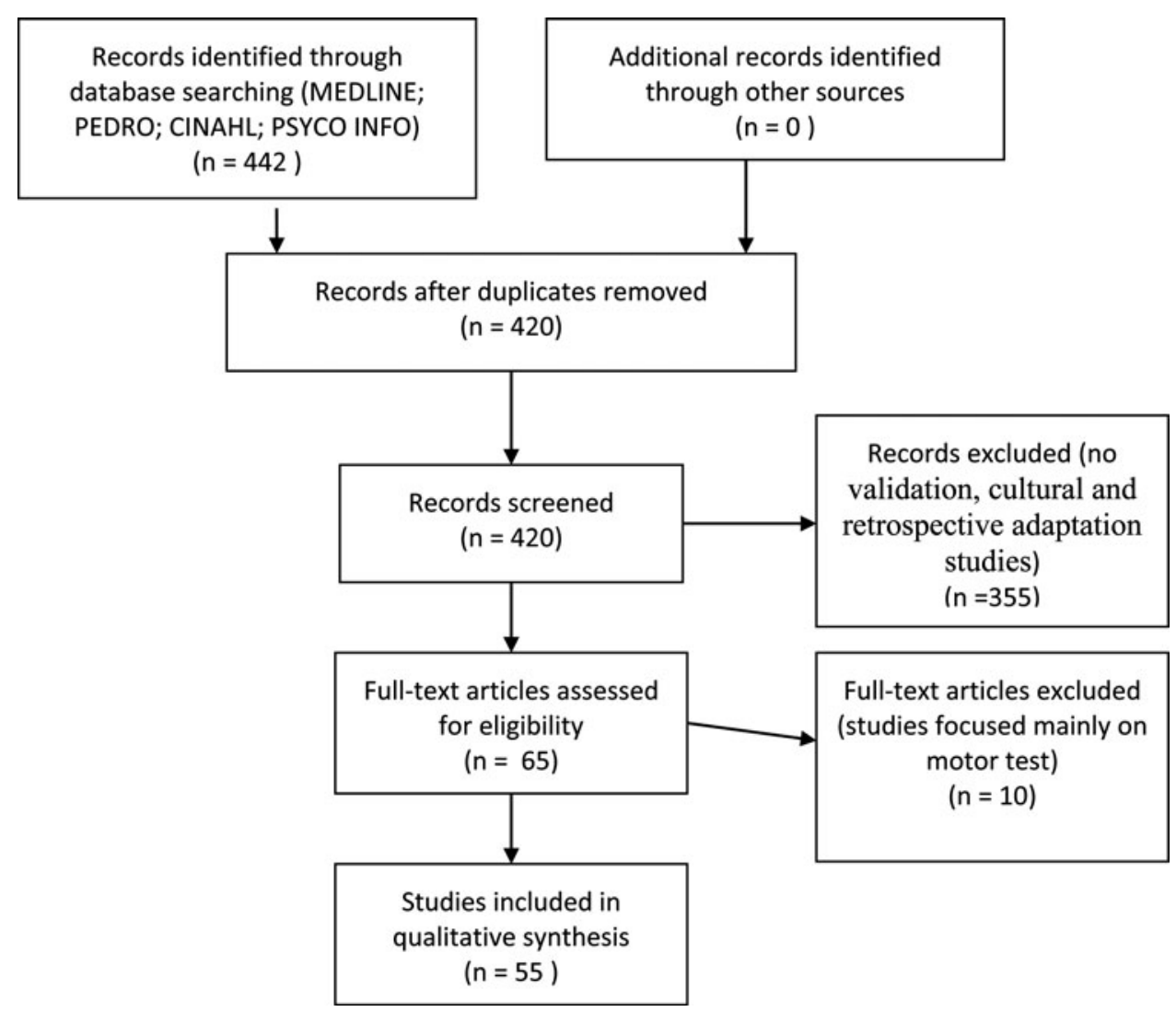

Figure 2. Flow chart. 


\section{Psychometric properties of each scale}

\section{Falls Efficay Scale Internationl (FES-I)}

The FES-I was the most represented instrument, conceived in English, ${ }^{6}$ and validated in other 12 languages: Persian, ${ }^{7}$ Greek, ${ }^{8}$ Portuguese, ${ }^{9}$ Swedish, ${ }^{10}$ Arabic, ${ }^{11}$ German, ${ }^{12}$ Norwegian, ${ }^{13}$ Dutch, ${ }^{12}$ Chinese, ${ }^{14}$ Spanish, ${ }^{15}$ Italian ${ }^{16}$ and Turkish. ${ }^{17}$ The FES-I was developed by members of the PRevention Of FAlls Network Europe (PROFANE) an organization that works to increase knowledge and capacity so as to reduce falls amongst older people, by the implementation of evidence-based intervention. The FES-I has been used to assess the fear of falling in community-dwelling older adults, it has also been validated in several pathologies, such as multiple sclerosis, osteoporosis in women, cognitive deficits, stroke, and menopause (Table 1). The FES-I consists of 16 items, 10 from the original version of the Falls Efficacy Scale (FES) and 6 additional items that evaluate more demanding physical and social activities. ${ }^{6}$ Falls efficacy is rated on a 4-point scale for each activity, where: $1=$ not at all concerned, $2=$ somewhat concerned, $3=$ fairly concerned and $4=$ very concerned. The total score ranged from 16 (no concern about falling) to 64 (severe concern about falling). The results suggest that the FES-I has good internal consistency with a Cronbach's $\alpha$ ranging from $0.78^{18}$ and $0.98 ;{ }^{16}$ Cronbach's $\alpha$ was $<0.90$ in only two of the studies analyzed. The ICC values have a wider spectrum ranging from $0.584^{19}$ and $0.99,{ }^{17}$ but in almost all the studies the values were $>0.80$, suggesting good reliability. The only ICC value $<0.70$ came from Hauer et al. $(2010)^{19}$ (ICC $\left.=0.584\right)$ and it refers to a subset of the sample; the value was related to self-administered FES-I in patients with cognitive impairment for whom the authors suggested that an interview would have been a better way to administer the questionnaire.

\section{Other FES versions}

The first version of the FES has 10 items, ${ }^{20}$ the short FES-I has 7 items, ${ }^{21}$ the Adapted FES versions has 11 items, ${ }^{22}$ the Modified FES version has 12 items $^{23}$ and the Iconographical Falls Efficacy Scale (ICON-FES) presents 30 -item and 10-item versions ${ }^{24,25}$ (Tables 2-4).

\section{Activities specific Balance Confidence Scale (ABC) 16 items and short versions}

The ABC scale was developed by Powell et al. (1995). ${ }^{26}$ It evaluates the fear of falling through personal balance confidence in older adults living in a community setting and it is easy to use. Participants rated their balance confidence on a scale of $0 \%$ (not confident) to $100 \%$ (completely confident) following a series of 16 questions regarding balance-challenging tasks. Balance confidence was scored as the mean of the responses and was reported as a confidence percentage. The 16-item version has been 


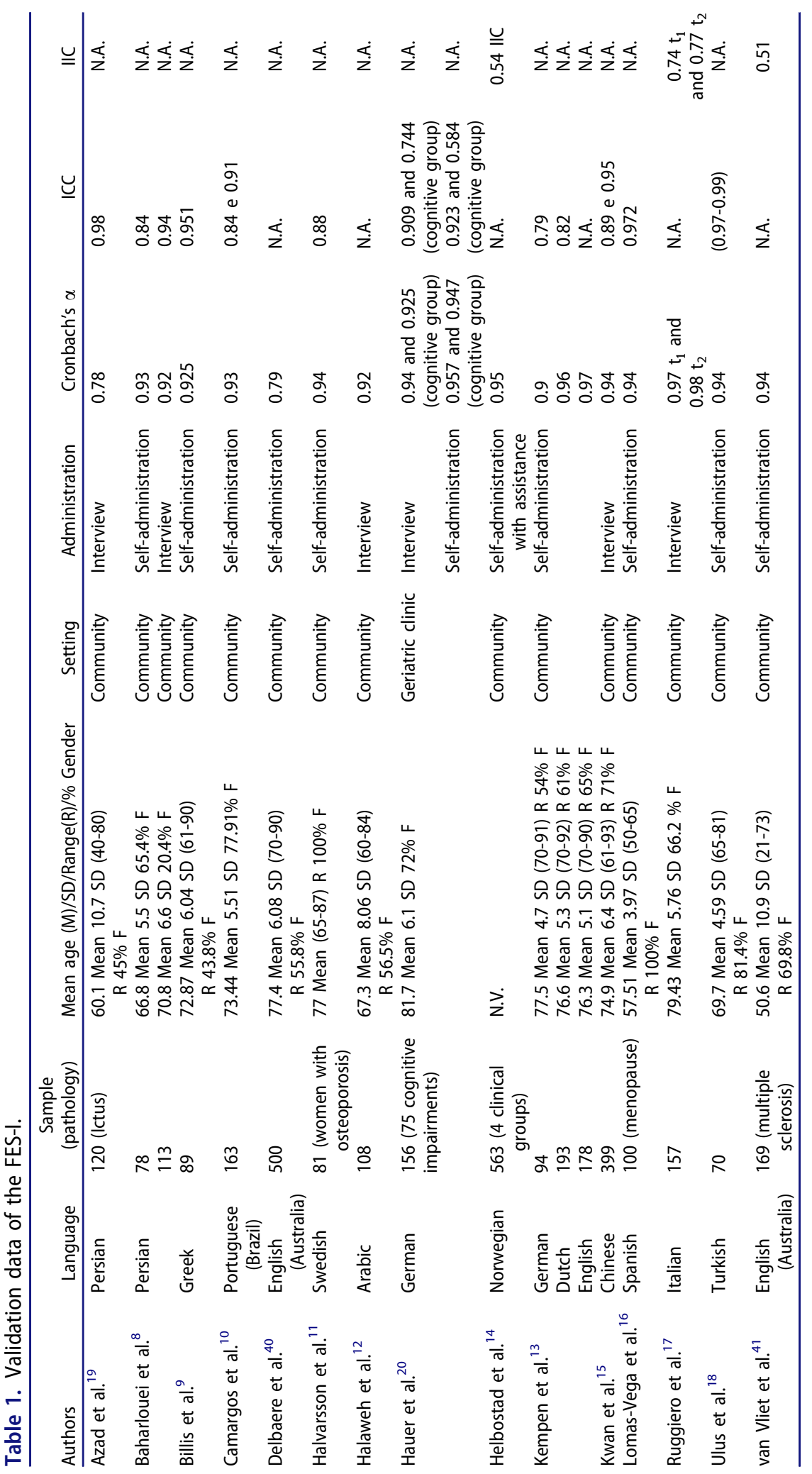




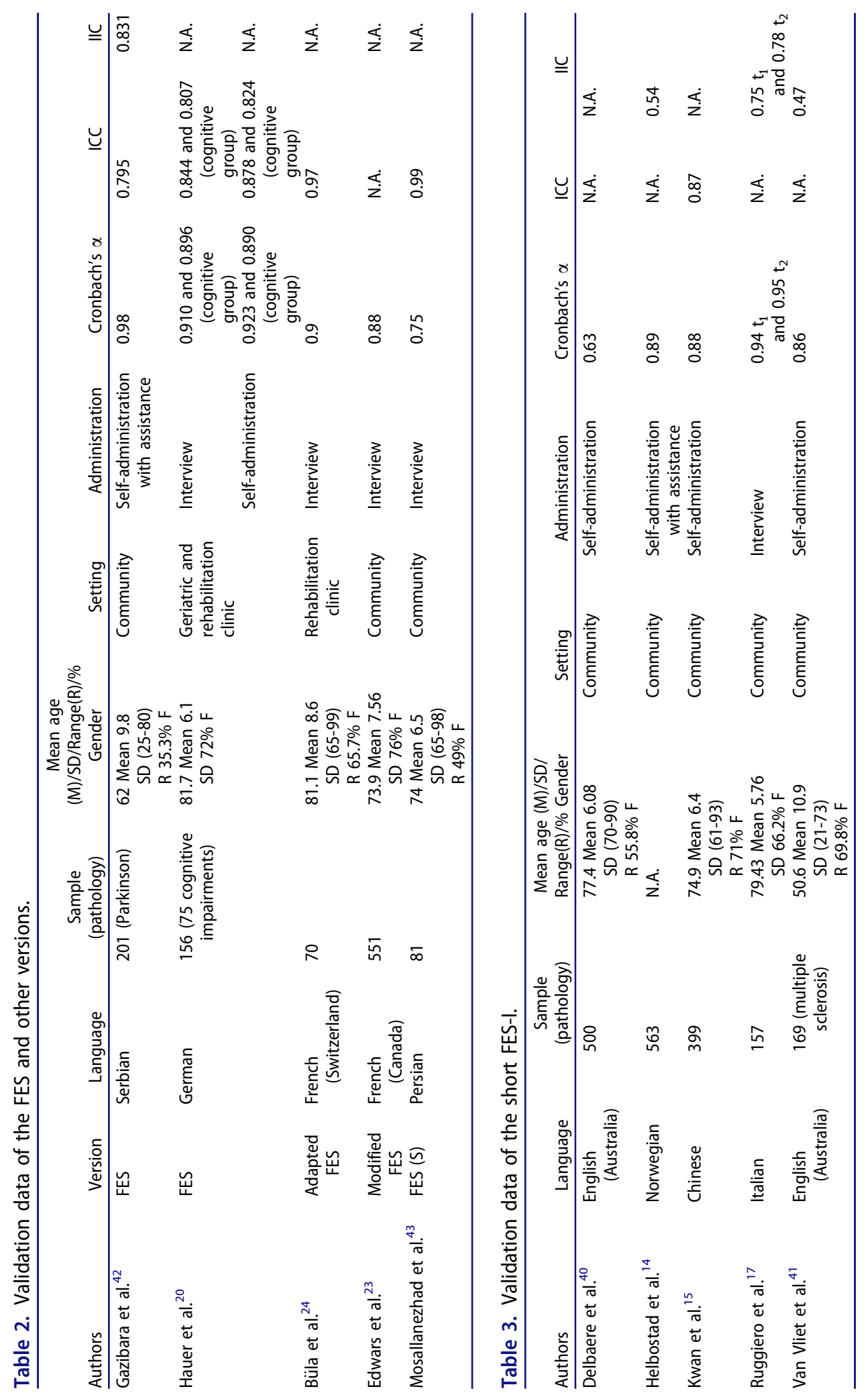




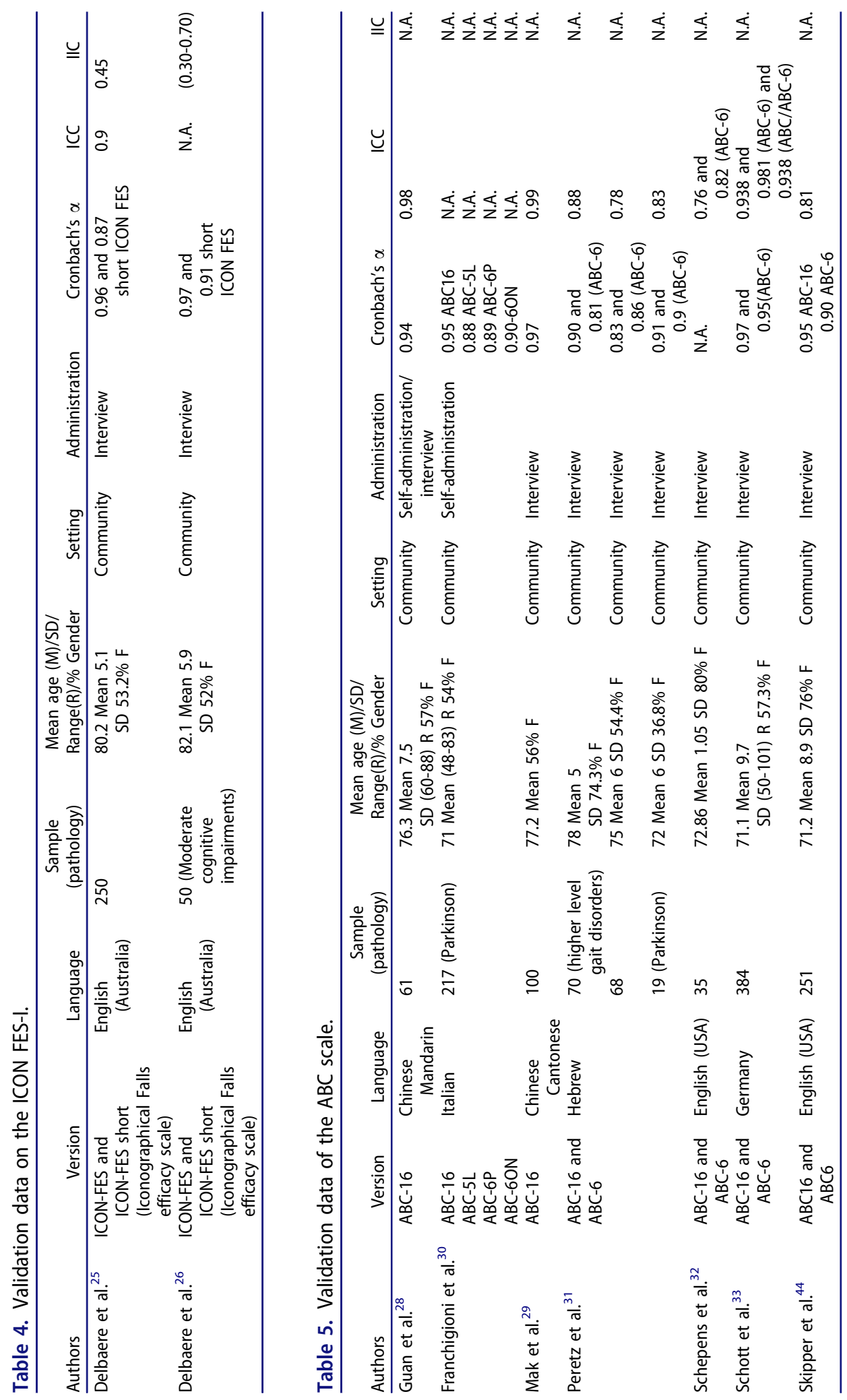


validated in five languages: Chinese, ${ }^{27,28}$ Italian, ${ }^{29}$ Hebrew, ${ }^{30}$ English, ${ }^{31}$ and German $^{32}$ and the short version in four languages: Italian, ${ }^{29}$ Hebrew, ${ }^{30}$ English, ${ }^{31}$ and German ${ }^{32}$ (Table 5). Data from the analyzed studies support the internal consistency of the $\mathrm{ABC}$ scale, Cronbach's $\alpha$ ranging from $0.81^{30}$ and $0.97 ;^{32}$ in fact, the items are strongly homogeneous. The ICC values ranging from $0.76^{31}$ and $0.981^{32}$ found by various studies express the relationship between the 16-item scale and the short versions and testretest reliability and confirm the reliability of the scale.

\section{St Thomas Risk Assessment Tool (STRATIFY)}

The STRATIFY scale, created by Oliver et al. (1997), ${ }^{33}$ has been validated in two languages: English, ${ }^{34,35}$ and Spanish. ${ }^{36}$ The STRATIFY scale assesses the risk of falling in hospitals. The evaluation is based on five questions asked of both the patient and the operator; administration time is 510 minutes. It evaluates five elements: previous falls, agitation, visual disturbances, frequency of evacuations, and transfer/mobility. The variables are dichotomic $(1=$ yes and $0=$ no). A score of 2 or greater indicates a high risk of falling. Webster et al. (2008) ${ }^{34}$ used the recommended cutoff point $(\geq 2)$ where the instrument had high sensitivity and negative predictability ( $82 \%$ and $97 \%)$, moderate specificity (62\%), but low positive predictability (18\%). Papaioannou et al. (2004) ${ }^{35}$ reported results related at two different cutoff point (sensitivity $91.2 \%$ and specificity $49.3 \%$ with cutoff $\geq 2$ and sensitivity $61.8 \%$ and specificity $71.3 \%$ with cutoff $\geq 3$ ). The third study was by Aranda-Gallardo et al. (2015), ${ }^{36}$ and is still in progress (Table 6).

\section{Other scales}

The research found 25 other validated tools; their validation data are presented in Table 7.

\section{Risk of bias within studies}

All the studies were evaluated with the Quality Assessment Tool for Observational Cohort and Cross-Sectional Studies. Only two studies ${ }^{37,38}$ had poor results due to a marked lack of data.

\section{Meta-analysis}

Topic of the review was to identify the validated fall risk assessment tools and assess their settings, language, pathology, and psychometric properties. The identified studies are too heterogeneous, so for the reported data, specific variables of interest, specific populations characteristics we didn't consider a meta-analysis. 


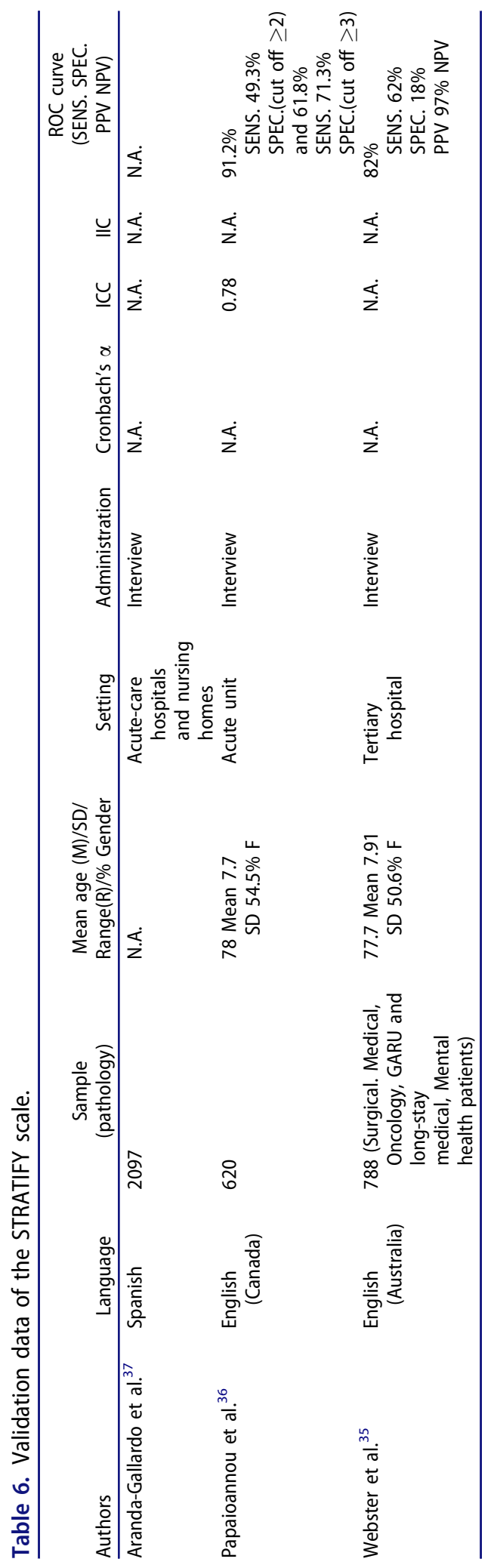




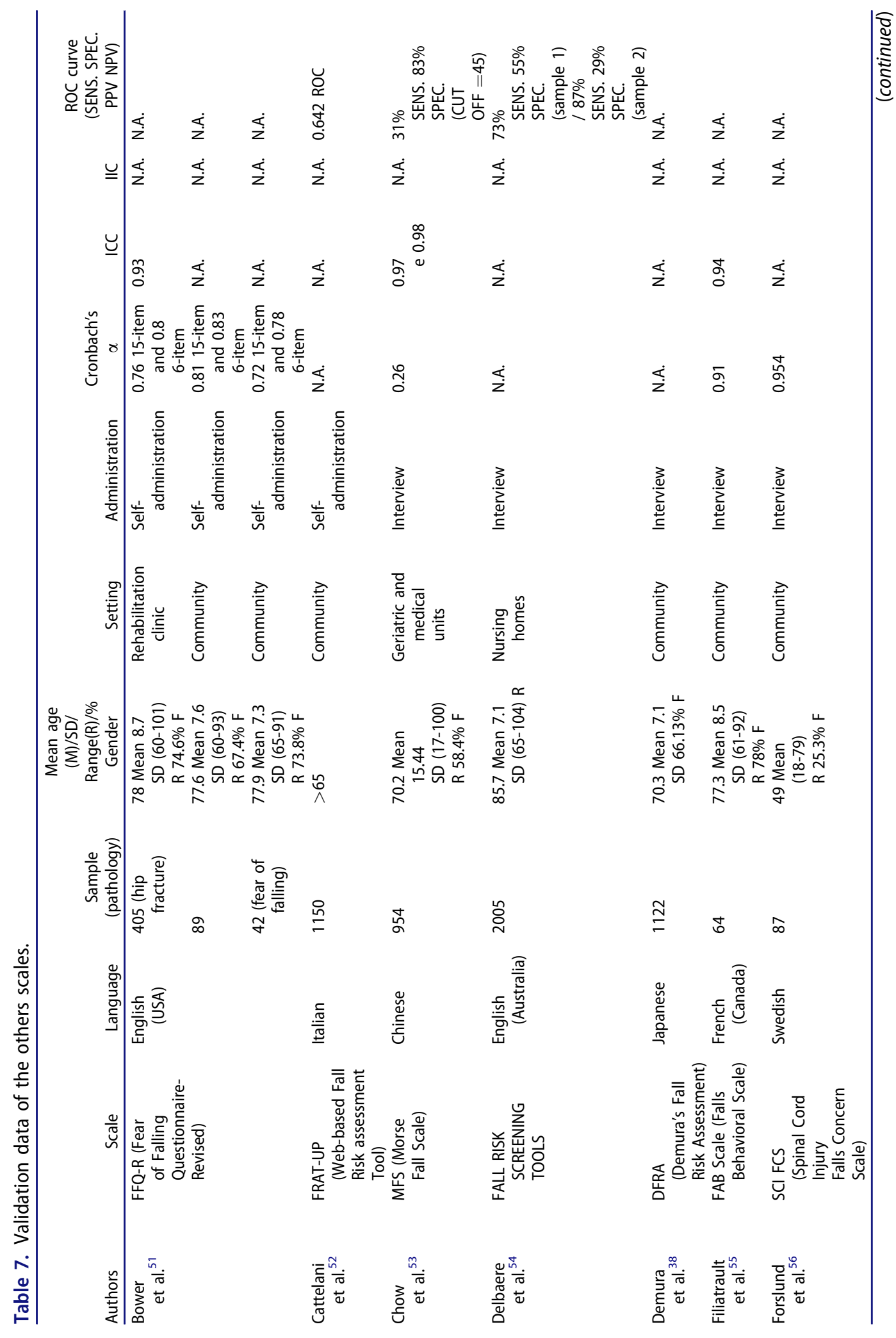




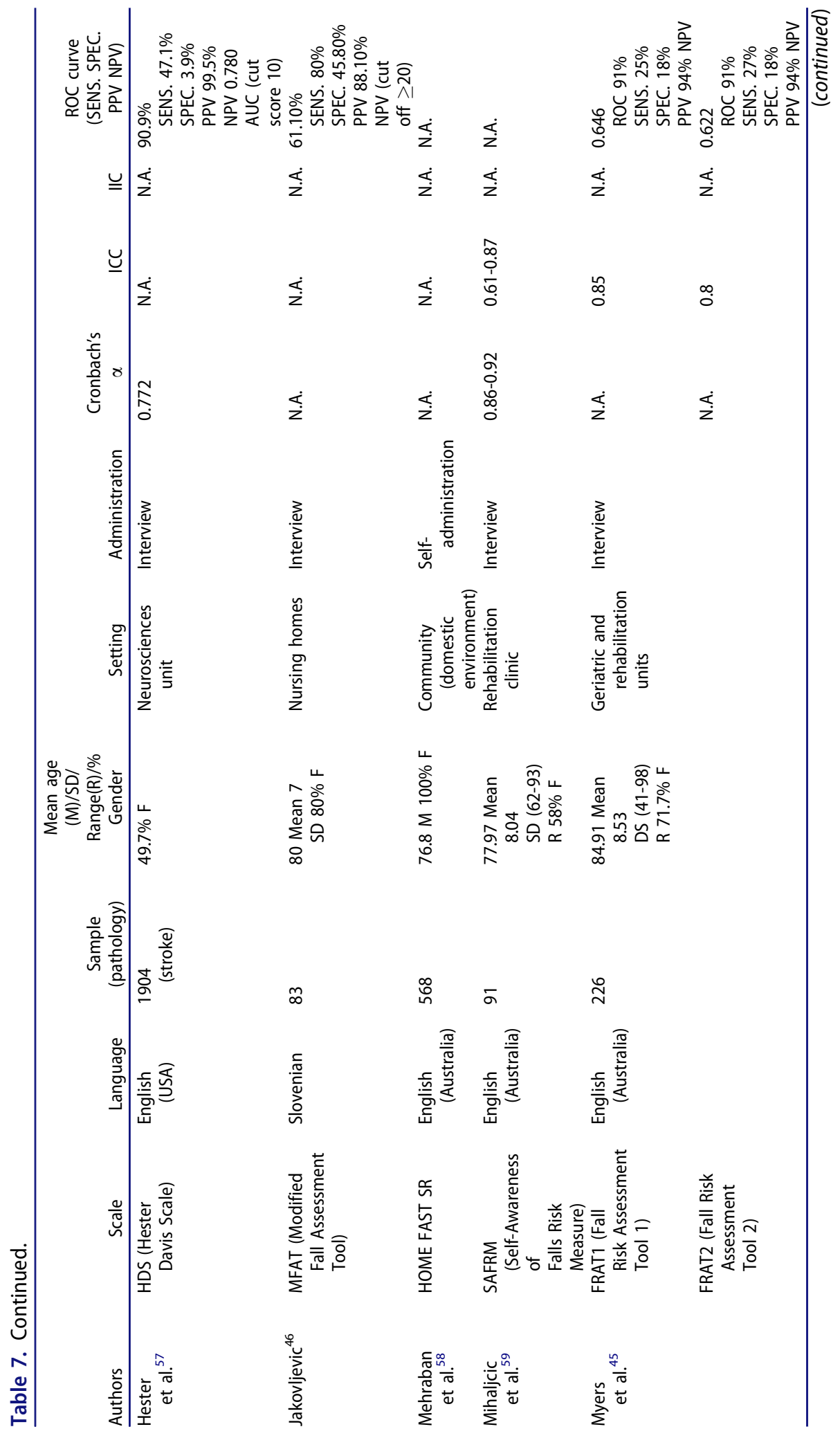




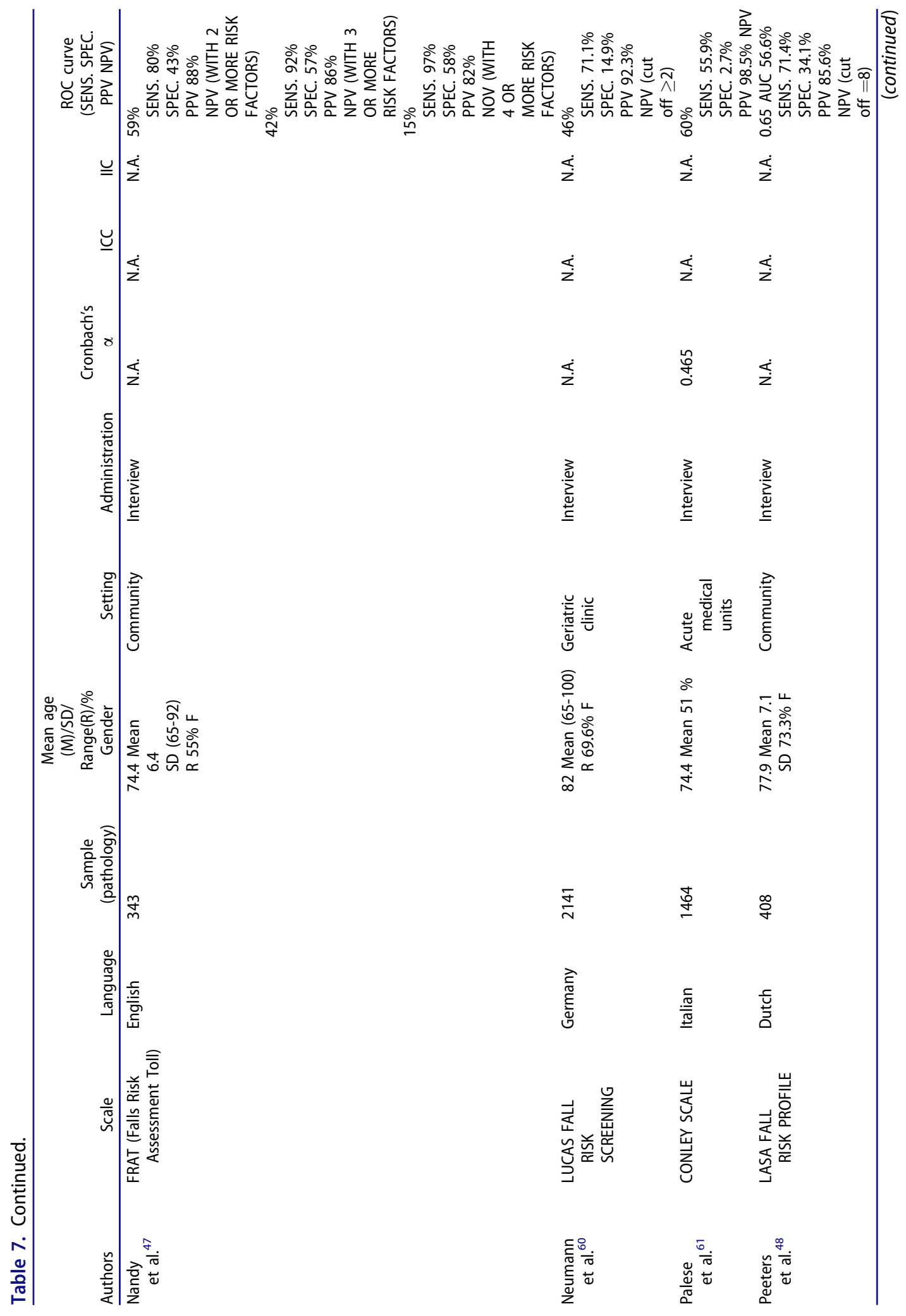




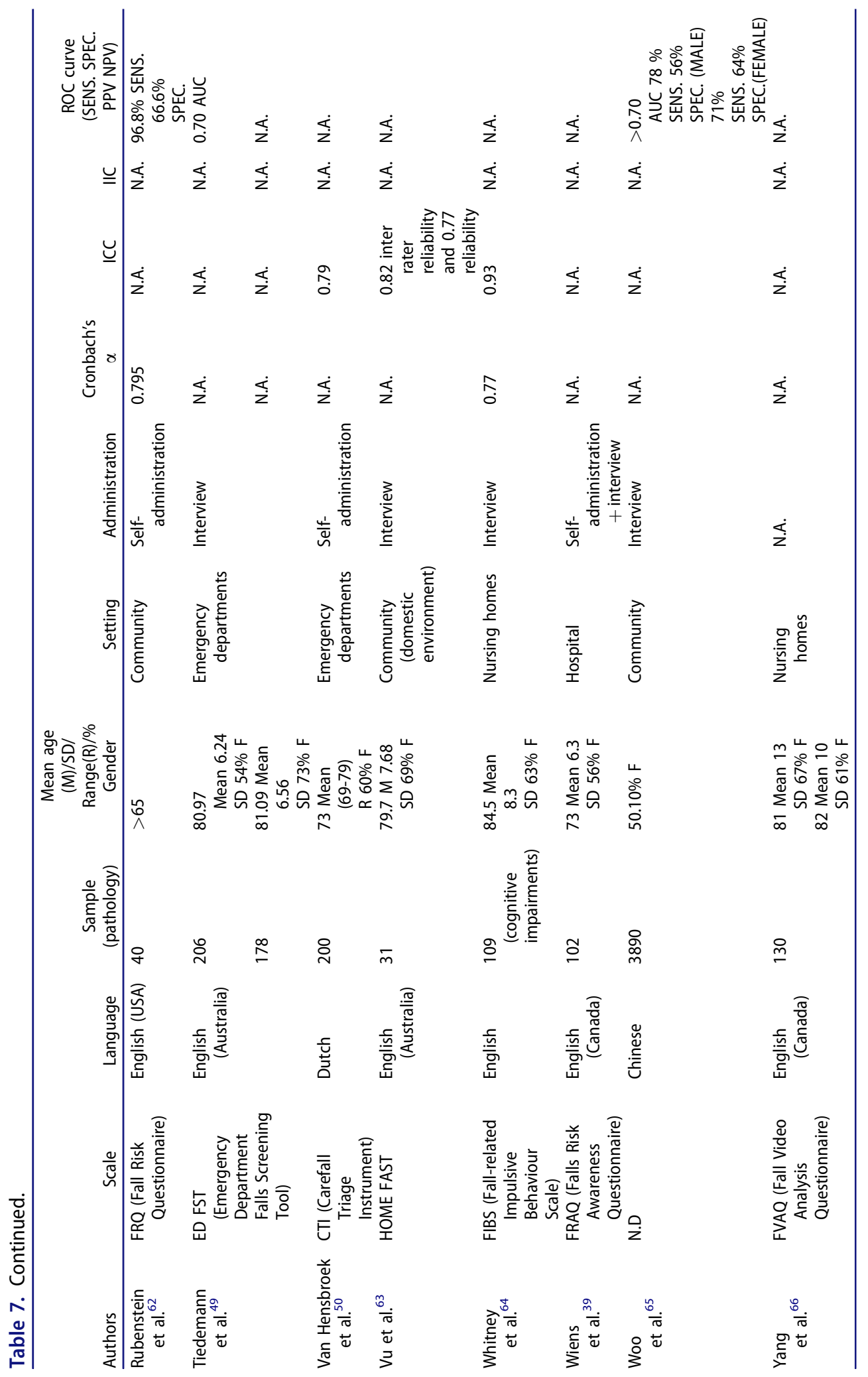




\section{Discussion}

\section{Summary of the quality of the evidence}

Falls are among the most serious problems of older adults, with high mortality and morbidity rates. Implementing preventive strategies is often effective, but it is not always possible because of poor resources. For this reason, it is crucial to properly identify individuals with a high fall risk to target resources better. In fact, medical associations and national health authorities recommend the adoption of valid fall risk assessment tools.

The first objective of the review was to identify fall risk assessment tools for older adults that have been validated on an international level. The second objective was to collect the scores of these tools, paying particular attention to the validation setting. The data available in the major databases up to February 2017 permit the identification of different fall risk assessment tools internationally. The research was conducted using keywords and no time limits were set so as not to exclude any study that could have made important contributions to the review. This review included 55 studies published between January 1979 and February 2017: 21 on the FES and its variants, 7 on the ABC scale, 3 on the STRATIFY scale, and the remaining 24 were related to other tools used less worldwide.

\section{Falls Efficacy Scale versions}

It is clear that the FES (and in particular, the international full version) is the most used tool. It has been translated into 13 different languages (English, ${ }^{6}$ Persian, ${ }^{7}$ Greek, ${ }^{8}$ Portuguese, ${ }^{9}$ Swedish, ${ }^{10}$ Arabic, ${ }^{11}$ German, ${ }^{12}$ Norwegian, ${ }^{13}$ Dutch, ${ }^{12}$ Chinese, ${ }^{14}$ Spanish, ${ }^{15}$ Italian $^{16}$ and Turkish ${ }^{17}$ ) and validated in healthy older adults as well as in various pathologies and frail older adults (stroke, osteoporosis in women, menopause, and multiple sclerosis). The results suggest that the FES-I has good reliability. In only one of the analyzed studies ${ }^{39}$ were predictive values studied and reported, the authors suggested a cutoff point to distinguish between low and strong fear of falling and two cutoff points to distinguish between low, moderate, and strong fear of falling. Future studies could investigate cutoff point in individuals with different pathologies and in different languages.

The results of this review shows that all FES versions have good reliability and they are validated in different languages (FES-I Short, ${ }^{13,14,16,39,40}$ FES first version, ${ }^{19,41,42}$ FES Modified and FES Adapted, ${ }^{22,23}$ FES iconographical $^{24}$ )

\section{Activities Specific Balance Confidence Scale (ABC)}

The second most used tool is the $A B C$ scale. It evaluates the fear of falling through personal balance confidence in older adults living in a community 
setting and it is also validated in individuals with Parkinson's disease. ${ }^{29}$ The 16-item version has been validated in five languages: Chinese, ${ }^{27,28}$ Italian, ${ }^{29}$ Hebrew, ${ }^{30}$ English, ${ }^{31}$ and German ${ }^{32}$ and the short version in four languages: Italian, ${ }^{29}$ Hebrew, ${ }^{30}$ English, ${ }^{31}$ and German. ${ }^{32}$ The results suggest the good reliability for all versions. Several authors ${ }^{30,31,43}$ claimed that the short version differentiates better than the integral version the subjects at risk of falling. The hypothesis is that this difference is due to the fact that the short version includes activities with a higher difficulty rate, and with 10 more items on the integral version, the final score could swell, expressing more confidence with the activities. In any case, the short version is valid and reliable, and since it requires the shortest amount of time for its administration, it is quite suitable for very busy clinics. ${ }^{30-32,43}$ From the analyzed studies, it is obvious that an interview is more reliable than self-administration, especially in older adults with low educational levels, because an interview allows them to understand the items and the compilation procedure better. None of the studies included in this review for the $A B C$ scale report predictive values, future studies could investigate these aspects.

\section{St Thomas Risk Assessment Tool (STRATIFY)}

The third most represented tool is the STRATIFY scale. It has been validated in two languages: English, ${ }^{34,35}$ and Spanish. ${ }^{36}$ The STRATIFY scale assesses the risk of falling in hospitals in patients with medical, surgical, mental, and oncological problems. The results are not very encouraging, in particular in the study of Webster et al. (2008), ${ }^{34} 82 \%$ of the patients at risk of falling did not fall (positive predictiveness 18\%), which makes the scale less useful clinically. A large number of false positives, in fact, can lead to the mismanagement of resources, with unnecessary targeting of people who are not at risk. Results for the Spanish version of the STRATIFY scale are not available yet, the study by Aranda-Gallardo et al. $(2015)^{36}$ is still in progress but, according to the authors, future findings on prediction will have strong evidence thanks to the number of samples.

\section{All scales}

The research found 25 other validated tools in 9 different languages. A setting stratification for all the 33 included tools indicates that the most effective tools in the hospital environment (medical units, geriatric clinics, and rehabilitation clinics) were the two Fall Risk Assessment Tools (FRATs) of Myers et al. (2003). ${ }^{44}$

The lack of much data from a few studies regarding validated instruments in nursing homes does not allow a conclusion, but the instrument of Jakovljevic (2009) ${ }^{45}$ appears to be the best analyzed. This questionnaire 
investigates previous falls, cognition, impulsive behavior, use of psychotropic medicines, incontinence and urgency, and environmental hazards, and the scale presents discrete predictive values. The authors recommended its use. From the many studies concerning the extra-hospital environment and community-dwelling older adults, only the FRAT by Nandy et al. $(2004)^{46}$ and the LASA fall risk profile by Peeters et al. (2010) ${ }^{47}$ reported all predictive values. The first investigates previous falls, drug use, neurological disorders, balance problems, and muscular strength and has a positive predictive value ranging from $43 \%$ to $58 \%$ depending on how many risk factors are present. The LASA fall risk profile investigates previous drops, dizziness, disability, grip strength, weight, pets, fear of falling, alcohol intake, and social level and has a positive predictive value of $34.1 \%$. However, only the first was recommended by the authors.

Finally, for emergency departments, the tools of Tiedemann et al. $(2013)^{48}$ and Boele Van Hensbroek et al. (2009) ${ }^{49}$ were validated but predictive values were not reported.

\section{Limitations of the study}

There are several limitations of this review that need to be considered. Despite having systematically searched three electronic databases, it is possible that not all relevant studies were identified. Studies may have been published in journals that were not covered by the databases. In addition, this review only included published studies; therefore, studies that have been submitted and not accepted for publication or were accepted for publication only recently would be excluded. Only English-language articles were included, making it possible that this systematic review is not a complete representation of the evidence available worldwide. Finally, studies may not have been identified with the search strategy used.

\section{Conclusions}

This study was conducted by a research group composed by medical doctors and rehabilitation professionals from the "Sapienza" University of Rome and from "Rehabilitation \& Outcome Measure Assessment" (R.O.M.A.) association. R.O.M.A. association in the last few years has dealt with several systematic reviews and the validation of many outcome measures in Italy. ${ }^{66-76}$

The data available in the literature before February 2017 allowed for the identification of 33 different fall risk assessment tools, but it is still not possible to identify one that is usable at any time and in any setting. Even with a setting stratification, it was not possible to reach definitive 
recommendations. Internationally, the most used tools are the FES-I and ABC scale. The FES-I has been validated in 13 languages; it uses 16 items to evaluate the fear of falling in community-dwelling older adults. The $\mathrm{ABC}$ scale has been validated in five languages; it evaluates the fear of falling through balance confidence in social and physical activities in community-dwelling older adults. Both tools are reliable. The large number of tools reflects a strong tendency to create new instruments, with only a few of them recommended. However, to reach a gold standard, it would be good to try to validate the existing scales instead of creating new ones.

\section{Conflict of interest}

The Authors declares that he has no conflict of interest.

\section{Statement of human and animal rights}

All procedures followed were in accordance with the ethical standards of the responsible committee on human experimentation (institutional and national) and with the Helsinki Declaration of 1975, as revised in 2008. Informed consent was obtained from all patients for being included in the study.

\section{Statement of informed consent}

Informed consent was obtained from all individual participants included in the study.

\section{Financial disclosures}

All authors have no commercial associations or disclosures that may pose or create a conflict of interest with the information presented within this manuscript.

\section{ORCID}

Giovanni Galeoto (D) http://orcid.org/0000-0002-9043-5686

\section{References}

1. In: Falls: Assessment and Prevention of Falls in Older People. London 2013.

2. Ang SGM, O'Brien AP, Wilson A. Fall concern about older persons shifts to carers as changing health policy focuses on family, home-based care. Singapore Med J. 2018; 59(1):9-11. 
3. Cameron ID, Gillespie LD, Robertson MC. Interventions for preventing falls in older people in care facilities and hospitals. Cochrane Database Syst Rev. 2012;12: CD005465.

4. Haines TP, Hill K, Walsh W, Osborne R. Design-related bias in hospital fall risk screening tool predictive accuracy evaluations: systematic review and meta-analysis. J Gerontol A Biol Sci Med Sci. 2007;62(6):664-672.

5. Scott V, Votova K, Scanlan A, Close J. Multifactorial and functional mobility assessment tools for fall risk among older adults in community, home-support, long-term and acute care settings. Age Ageing. 2007;36(2):130-139.

6. Yardley L, Beyer N, Hauer K, Kempen G, Piot-Ziegler C, Todd C. Development and initial validation of the Falls Efficacy Scale-International (FES-I). Age Ageing. 2005; 34(6):614-619.

7. Baharlouei H, Salavati M, Akhbari B, Mosallanezhad Z, Mazaheri M, Negahban H. Cross-cultural validation of the Falls Efficacy Scale International (FES-I) using selfreport and interview-based questionnaires among Persian-speaking elderly adults. Arch Gerontol Geriatr. 2013;57(3):339-344.

8. Billis E, Strimpakos N, Kapreli E, et al. Cross-cultural validation of the Falls Efficacy Scale International (FES-I) in Greek community-dwelling older adults. Disabil Rehabil. 2011;33(19-20):1776-1784.

9. Camargos FF, Dias RC, Dias JM, Freire MT. Cross-cultural adaptation and evaluation of the psychometric properties of the Falls Efficacy Scale-International Among Elderly Brazilians (FES-I-BRAZIL). Rev Bras Fisioter. 2010;14(3):237-243.

10. Halvarsson A, Franzen E, Stahle A. Assessing the relative and absolute reliability of the Falls Efficacy Scale-International questionnaire in elderly individuals with increased fall risk and the questionnaire's convergent validity in elderly women with osteoporosis. Osteoporos Int. 2013;24(6):1853-1858.

11. Halaweh H, Svantesson U, Rosberg S, Willen C. Cross-cultural adaptation, validity and reliability of the arabic version of the falls efficacy scale-international (FES-I). Med Princ Pract. 2016;25(1):1-7.

12. Kempen GI, Todd CJ, Van Haastregt JC. Cross-cultural validation of the Falls Efficacy Scale International (FES-I) in older people: results from Germany, the Netherlands and the UK were satisfactory. Disabil Rehabil. 2007;29(2):155-162.

13. Helbostad JL, Taraldsen K, Granbo R, Yardley L, Todd CJ, Sletvold O. Validation of the Falls Efficacy Scale-International in fall-prone older persons. Age Ageing. 2010; 39(2):259

14. Kwan MM, Tsang WW, Close JC, Lord SR. Development and validation of a Chinese version of the Falls Efficacy Scale International. Arch Gerontol Geriatr. 2013;56(1): 169-174.

15. Lomas-Vega R, Hita-Contreras F, Mendoza N, Martinez-Amat A. Cross-cultural adaptation and validation of the Falls Efficacy Scale International in Spanish postmenopausal women. Menopause 2012;19(8):904-908.

16. Ruggiero C, Mariani T, Gugliotta R, et al. Validation of the Italian version of the falls efficacy scale international (FES-I) and the short FES-I in community-dwelling older persons. Arch Gerontol Geriatr. 2009;49 (Suppl 1):211-219.

17. Ulus Y, Durmus D, Akyol Y, Terzi Y, Bilgici A, Kuru O. Reliability and validity of the Turkish version of the Falls Efficacy Scale International (FES-I) in communitydwelling older persons. Arch Gerontol Geriatr. 2012;54(3):429-433. 
18. Azad A, Hassani Mehraban A, Mehrpour M, Mohammadi B. Clinical assessment of fear of falling after stroke: validity, reliability and responsiveness of the Persian version of the Fall Efficacy Scale-International. Med J Islam Repub Iran 2014;28:131.

19. Hauer K, Yardley L, Beyer N, et al. Validation of the falls efficacy scale and falls efficacy scale international in geriatric patients with and without cognitive impairment: results of self-report and interview-based questionnaires. Gerontology 2010;56(2): 190-199.

20. Tinetti ME, Richman D, Powell L. Falls efficacy as a measure of fear of falling. J Gerontol. 1990;45(6):P239-P243.

21. Kempen GI, Yardley L, van Haastregt JC, et al. The Short FES-I: a shortened version of the falls efficacy scale-international to assess fear of falling. Age Ageing. 2008; 37(1):45-50.

22. Edwards N, Lockett D. Development and validation of a modified falls-efficacy scale. Disabil Rehabil Assist Technol. 2008;3(4):193-200.

23. Bula CJ, Martin E, Rochat S, Piot-Ziegler C. Validation of an adapted falls efficacy scale in older rehabilitation patients. Arch Phys Med Rehabil. 2008;89(2):291-296.

24. Delbaere K, Smith ST, Lord SR. Development and initial validation of the Iconographical Falls Efficacy Scale. J Gerontol A Biol Sci Med Sci. 2011;66(6): 674-680.

25. Delbaere K, Close JC, Taylor M, Wesson J, Lord SR. Validation of the Iconographical Falls Efficacy Scale in cognitively impaired older people. J Gerontol A Biol Sci Med Sci. 2013;68(9):1098-1102.

26. Powell LE, Myers AM. The Activities-specific Balance Confidence (ABC) Scale. J Gerontol A Biol Sci Med Sci. 1995;50A(1):M28-M34.

27. Guan Q, Han H, Li Y, Zhao L, Jin L, Zhan Q. Activities-specific Balance Confidence (ABC) Scale adapted for the mainland population of China. Clin Rehabil. 2012;26(7): 648-655.

28. Mak MK, Lau AL, Law FS, Cheung CC, Wong IS. Validation of the Chinese translated activities-specific balance confidence scale. Arch Phys Med Rehabil. 2007;88(4): 496-503.

29. Franchignoni F, Giordano A, Ronconi G, Rabini A, Ferriero G. Rasch validation of the Activities-specific Balance Confidence Scale and its short versions in patients with Parkinson's disease. J Rehabil Med. 2014;46(6):532-539.

30. Peretz C, Herman T, Hausdorff JM, Giladi N. Assessing fear of falling: Can a short version of the Activities-specific Balance Confidence scale be useful? Mov Disord. 2006;21(12):2101-2105.

31. Schepens S, Goldberg A, Wallace M. The short version of the Activities-specific Balance Confidence $(\mathrm{ABC})$ scale: its validity, reliability, and relationship to balance impairment and falls in older adults. Arch Gerontol Geriatr. 2010;51(1):9-12.

32. Schott N. Reliability and validity of the German short version of the Activities specific Balance Confidence (ABC-D6) scale in older adults. Arch Gerontol Geriatr. 2014;59(2):272-279.

33. Oliver D, Britton M, Seed P, Martin FC, Hopper AH. Development and evaluation of evidence based risk assessment tool (STRATIFY) to predict which elderly inpatients will fall: case-control and cohort studies. Bmj. 1997;315(7115):1049-1053.

34. Webster J, Courtney M, O'Rourke P, et al. Should elderly patients be screened for their 'falls risk'? Validity of the STRATIFY falls screening tool and predictors of falls in a large acute hospital. Age Ageing. 2008;37(6):702-706. 
35. Papaioannou A, Parkinson W, Cook R, Ferko N, Coker E, Adachi JD. Prediction of falls using a risk assessment tool in the acute care setting. BMC Med. 2004;2:1.

36. Aranda-Gallardo M, Enriquez de Luna-Rodriguez M, Canca-Sanchez JC, MoyaSuarez AB, Morales-Asencio JM. Validation of the STRATIFY falls risk-assessment tool for acute-care hospital patients and nursing home residents: study protocol. J Adv Nurs. 2015;71(8):1948-1957.

37. Demura S, Sato S, Yamaji S, Kasuga K, Nagasawa Y. Examination of validity of fall risk assessment items for screening high fall risk elderly among the healthy community-dwelling Japanese population. Arch Gerontol Geriatr. 2011;53(1):e41-e45.

38. Wiens CA, Koleba T, Jones CA, Feeny DF. The Falls Risk Awareness Questionnaire: development and validation for use with older adults. J Gerontol Nurs 2006;32(8): 43-50.

39. Delbaere K, Close JC, Mikolaizak AS, Sachdev PS, Brodaty H, Lord SR. The Falls Efficacy Scale International (FES-I). A comprehensive longitudinal validation study. Age Ageing. 2010;39(2):210-216.

40. van Vliet R, Hoang P, Lord S, Gandevia S, Delbaere K. Falls efficacy scale-international: a cross-sectional validation in people with multiple sclerosis. Arch Phys Med Rehabil. 2013;94(5):883-889.

41. Gazibara T, Stankovic I, Tomic A, et al. Validation and cross-cultural adaptation of the Falls Efficacy Scale in patients with Parkinson's disease in Serbia. Geriatr Gerontol Int. 2013;13(4):936-941.

42. Mosallanezhad Z, Salavati M, Hellström K, Reza Sotoudeh G, Nilsson Wikmar L, Frändin K. Cross-cultural adaptation, reliability and validity of the Persian version of the Modified Falls Efficacy Scale. Disabil Rehabil. 2011;33(25-26):2446-2453.

43. Skipper A, Ellis R. Examining the Validity and Reliability of the ABC-6 in Underserved Older Adults. J Appl Gerontol. 2015;34(6):761-778.

44. Myers H, Nikoletti S. Fall risk assessment: a prospective investigation of nurses' clinical judgement and risk assessment tools in predicting patient falls. Int J Nurs Pract. 2003;9(3):158-165.

45. Jakovljevic M. Predictive validity of a modified fall assessment tool in nursing homes: experience from Slovenia. Nurs Health Sci. 2009;11(4):430-435.

46. Nandy S, Parsons S, Cryer C, et al. Development and preliminary examination of the predictive validity of the Falls Risk Assessment Tool (FRAT) for use in primary care. J Public Health (Oxf). 2004;26(2):138-143.

47. Peeters GM, Pluijm SM, van Schoor NM, Elders PJ, Bouter LM, Lips P. Validation of the LASA fall risk profile for recurrent falling in older recent fallers. J Clin Epidemiol. 2010;63(11):1242-1248.

48. Tiedemann A, Sherrington C, Orr T, et al. Identifying older people at high risk of future falls: development and validation of a screening tool for use in emergency departments. Emerg Med J. 2013;30(11):918-922.

49. Boele van Hensbroek P, van Dijk N, van Breda GF, et al. The CAREFALL Triage instrument identifying risk factors for recurrent falls in elderly patients. Am J Emerg Med. 2009;27(1):23-36.

50. Bower ES, Wetherell JL, Merz CC, Petkus AJ, Malcarne VL, Lenze EJ. A new measure of fear of falling: psychometric properties of the fear of falling questionnaire revised (FFQ-R). Int Psychogeriatr. 2015;27(07):1121-1133.

51. Cattelani L, Palumbo P, Palmerini L, et al. FRAT-up, a Web-based fall-risk assessment tool for elderly people living in the community. J Med Internet Res. 2015; 17(2):e41 
52. Chow SK, Lai CK, Wong TK, et al. Evaluation of the Morse Fall Scale: applicability in Chinese hospital populations. Int J Nurs Stud. 2007;44(4):556-565.

53. Delbaere K, Close JC, Menz HB, et al. Development and validation of fall risk screening tools for use in residential aged care facilities. Med J Aust. 2008;189(4):193-196.

54. Filiatrault J, Demers L, Parisien M, et al. Development and validation of a French Canadian version of the Falls Behavioral (FaB) Scale. Disabil Rehabil. 2014;36(21): 1798-1803.

55. Butler Forslund E, Roaldsen KS, Hultling C, Wahman K, Franzen E. Concerns about falling in wheelchair users with spinal cord injury-validation of the Swedish version of the spinal cord injury falls concern scale. Spinal Cord. 2016;54(2):115-119.

56. Hester AL, Davis DM. Validation of the Hester Davis Scale for fall risk assessment in a neurosciences population. J Neurosci Nurs. 2013;45(5):298-305.

57. Hassani Mehraban A, Mackenzie LA, Byles JE. A self-report home environment screening tool identified older women at risk of falls. J Clin Epidemiol. 2011;64(2): 191-199.

58. Mihaljcic T, Haines TP, Ponsford JL, Stolwyk RJ. Development of a new self-awareness of falls risk measure (SAFRM). Arch Gerontol Geriatr. 2014;59(2):249-256.

59. Neumann L, Hoffmann VS, Golgert S, Hasford J, Von Renteln-Kruse W. In-hospital fall-risk screening in 4,735 geriatric patients from the LUCAS project. J Nutr Health Aging. 2013;17(3):264-269.

60. Palese A, Gonella S, Lant A, et al. Post-hoc validation of the Conley Scale in predicting the risk of falling with older in-hospital medical patients: findings from a multicentre longitudinal study. Aging Clin Exp Res. 2016;28(1):139-146.

61. Rubenstein LZ, Vivrette R, Harker JO, Stevens JA, Kramer BJ. Validating an evidence-based, self-rated fall risk questionnaire (FRQ) for older adults. J Safety Res. 2011;42(6):493-499.

62. $\mathrm{Vu} \mathrm{TV}$, Mackenzie L. The inter-rater and test-retest reliability of the Home Falls and Accidents Screening Tool. Aust Occup Ther J. 2012;59(3):235-242.

63. Whitney J, Jackson SH, Close JC, Lord SR. Development and validation of a fallrelated impulsive behaviour scale for residential care. Age Ageing. 2013;42(6):754-758.

64. Woo J, Leung J, Wong S, Kwok T, Lee J, Lynn H. Development of a simple scoring tool in the primary care setting for prediction of recurrent falls in men and women aged 65 years and over living in the community. J Clin Nurs. 2009;18(7):1038-1048.

65. Yang Y, Schonnop R, Feldman F, Robinovitch SN. Development and validation of a questionnaire for analyzing real-life falls in long-term care captured on video. BMC Geriatr. 2013;13(1):40.

66. Galeoto G, Lauta A, Palumbo A, Castiglia SF, Mollica R, Santilli V. The Barthel Index: Italian translation, adaptation and validation. Int J Neurol Neurother. 2015; 2(1):1-7.

67. Culicchia G, Nobilia M, Asturi M, et al. Cross-cultural adaptation and validation of the Jebsen-Taylor hand function test in an Italian population. Rehabilitation Research and Practice. 2016;2016:1.

68. Castiglia SF, Galeoto G, Lauta A, et al. The culturally adapted Italian version of the Barthel Index (IcaBI): assessment of structural validity, inter-rater reliability and responsiveness to clinically relevant improvements in patients admitted to inpatient rehabilitation centers. Functional Neurology. 2017;32(4):221.

69. Marquez MA, De Santis R, Ammendola V, et al. Cross-cultural adaptation and validation of the "Spinal Cord Injury-Falls Concern Scale" in the Italian population. Spinal Cord 2018;1. 
70. Galeoto G, Sansoni J, Scuccimarri M, et al. A Psychometric Properties Evaluation of the Italian Version of the Geriatric Depression Scale. Depression Research and Treatment. 2018;2018:1.

71. Murgia M, Bernetti A, Delicata M, et al. Inter-and intra-interviewer reliability of Italian version of Pediatric Evaluation of Disability Inventory. Ann Ig 2018;30: 153-161.

72. Berardi A, De Santis R, Tofani M, et al. The Wheelchair Use Confidence Scale: Italian translation, adaptation, and validation of the short form. Disability and Rehabilitation: Assistive Technology 2017:1-6.

73. Tofani M, Candeloro C, Sabbadini M, et al. The psychosocial impact of assistive device scale: Italian validation in a cohort of nonambulant people with neuromotor disorders. Assistive Technology. 2018;1.

74. Galeoto G, Berardi A, De Santis R, et al. Validation and cross-cultural adaptation of the Van Lieshout test in an Italian population with cervical spinal cord injury: a psychometric study. Spinal Cord Ser Cases. 2018;4(1):49.

75. Parente M, Tofani M, De Santis R, Esposito G, Santilli V, Galeoto G. The role of the occupational therapist in disaster areas: systematic review. Occup Ther Int. 2017; 2017:6474761

76. Massai P, Colalelli F, Sansoni J, et al. Reliability and Validity of the Geriatric Depression Scale in Italian Subjects with Parkinson's Disease. Parkinson's Disease. 2018;2018:6. ID: 7347859. 